\title{
Determination of six sulfonylurea herbicides in environmental water samples by magnetic solid-phase extraction using multi-walled carbon nanotubes as adsorbents coupled with high-performance liquid chromatography
}

\author{
Jiping Ma ${ }^{\mathrm{a}, *}$, Lianhua Jiang ${ }^{\mathrm{a}}$, Gege $\mathrm{Wu}^{\mathrm{a}}$, Yan Xia ${ }^{\mathrm{a}}$, Wenhui Lu ${ }^{\mathrm{b}}$, Jinhua $\mathrm{Li}^{\mathrm{b}}$, \\ Lingxin Chen ${ }^{\mathrm{b}, *}$ \\ a School of Environmental \& Municipal Engineering, Qingdao Technological University, Qingdao 266033, China \\ ${ }^{\mathrm{b}}$ Key Laboratory of Coastal Environmental Processes and Ecological Remediation, Shandong Provincial Key Laboratory of Coastal Environmental Processes, \\ Yantai Institute of Coastal Zone Research, Chinese Academy of Sciences, Yantai 264003, China
}

\section{A R T I C L E I N F O}

\section{Article history:}

Received 25 March 2016

Received in revised form 26 August 2016

Accepted 29 August 2016

Available online 30 August 2016

\section{Keywords:}

Sulfonylurea herbicides

Magnetic solid-phase extraction

Multi-walled carbon nanotubes

Water samples

High-performance liquid chromatography

\begin{abstract}
A B S T R A C T
Magnetic solid-phase extraction (MSPE) using magnetic multi-walled carbon nanotubes (mag-MWCNTs) as adsorbents, coupled with high-performance liquid chromatography-diode-array detector (HPLC-DAD), was developed for the simultaneous separation and determination of six types of sulfonylurea herbicides (SUs) in environmental water samples. Several variables affecting MSPE efficiency were systematically investigated, including the type and volume of desorption solvent, sample solution $\mathrm{pH}$, salt concentration, amount of mag-MWCNTs, and extraction and desorption time. Response surface was employed to assist in the MSPE optimization. Under optimized conditions, excellent linearity was achieved in the range of $0.05-5.0 \mu \mathrm{g} / \mathrm{L}$ for all six SUs, with coefficients of correlation $r>0.9994$, and preconcentration factors ranging from 178 to 210 . Limits of detection and quantification were $0.01-0.04 \mu \mathrm{g} / \mathrm{L}$ and $0.03-0.13 \mu \mathrm{g} / \mathrm{L}$, respectively. The intra-day and inter-day precision (relative standard deviations, $n=6$, \%) at three spiked levels were $2.0-11.0 \%$ and $2.1-12.9 \%$ in terms of peak area, respectively. The method recoveries at three fortified concentrations were obtained within $76.7-106.9 \%$ for reservoir water samples and $78.2-105.4 \%$ for tap water samples. The developed MSPE-HPLC method demonstrated high sensitivity, repeatability, simplicity, rapidity, and excellent practical applicability.
\end{abstract}

(c) 2016 Elsevier B.V. All rights reserved.

\section{Introduction}

Sulfonylurea herbicides (SUs) are one class of widely used herbicides with high efficiency and low toxicity. These herbicides provide efficient, broad-spectrum control of broad-leaved weeds and some grasses. To date the class has expanded to include over 30 commercial herbicides. These compounds generally have low mammalian toxicity, but plants demonstrate a wide range of sensitivities to SUs. Some have demonstrated residual phytotoxicity, including rotation crops such as corn, sunflowers, sugar beets and dry beans [1]. SUs can be released into environmental water and endanger human health. Hence, the presence and levels of SUs in environmental water must be monitored and detected.

\footnotetext{
* Corresponding authors.

E-mail addresses: majiping2012@163.com (J. Ma), lxchen@yic.ac.cn (L. Chen).
}

Determination of trace SUs is very challenging. The most common analytical methods for SUs are high-performance liquid chromatography coupled with an ultraviolet or diode-array detector (HPLC-UV/DAD) [2-6] and mass spectrometry (HPLC-MS) [7,8]. However, for low concentration of SUs in water, UV detectors cannot provide high sensitivity without enrichment prior to analysis. HPLC-MS instrumentation is expensive and not available in every laboratory. Therefore, pretreatment techniques are imperative for the enrichment and cleanup of SUs in environmental samples in order to achieve the ideal sensitivity and effectively eliminate contaminants from complex matrices. Currently reported pretreatment techniques for SUs in environmental water samples mainly include solid-phase extraction (SPE) $[2,5,7,8]$, dispersive liquid-liquid microextraction [4], stir-bar sorptive extraction [9], and salting-out assisted liquid-liquid extraction [10]. SPE, due to its high recovery, short extraction time, high enrichment factor, low consumption of organic solvents, and ease of automation and 
<smiles>COc1cc(OC)nc(NC(=O)NS(=O)(=O)c2ncccc2C(=O)N(C)C)n1</smiles>

nicosulfuron<smiles>COC(=O)c1ccc(S(=O)(=O)NC(=O)Nc2nc(C)nc(OC)n2)s1</smiles>

thifensulfuron-methyl<smiles>C=C(OC)c1ccccc1S(=O)(=O)NC(=O)Nc1nc(C)nc(OCC)n1</smiles>

metsulfuron-methyl<smiles>COc1nc(C)nc(NC(=O)NS(=O)(=O)c2ccccc2Cl)n1</smiles>

chlorsulfuron<smiles>C=C(OCC)c1cn[nH]c1S(=O)(=O)NC(=O)Nc1nc(OC)cc(OC)n1</smiles>

pyrazosulfuron-ethyl<smiles>C=C(OCC)c1ccccc1S(=O)(=O)NC(=O)Nc1nc(Cl)cc(OC)n1</smiles>

chlorimuron-ethyl

Fig. 1. Chemical structures of six analyzed SUs.

operation, has been widely used to concentrate organic compounds in water samples. In SPE, the choice of adsorbents is very important for obtaining high-enrichment efficiency.

Magnetic SPE (MSPE) has received increasing attention as a relatively new mode of SPE based on the adsorption and release of target analytes by a small amount of magnetic nanoparticles (e.g., $\mathrm{Fe}_{3} \mathrm{O}_{4}$ nanoparticles) dispersed in solution. The $\mathrm{Fe}_{3} \mathrm{O}_{4}$ nanoparticle-adsorbed target compounds can be easily collected by an external magnetic field without additional centrifugation or filtration of samples [11,12]. For example, He et al. [13] have used $\mathrm{Fe}_{3} \mathrm{O}_{4} @$ dioctadecyl dimethyl ammonium chloride@silica magnetic particles as MSPE adsorbents for enrichment of SUs in environmental water samples.

Carbon nanotubes (CNTs) have also attracted much interest owing to their unique thermal, mechanical, electronic and chemical properties [14]. Multi-walled CNTs (MWCNTs) composed of several layers of rolled graphite sheets display large specific surface areas and have high adsorption capacities, making them especially useful [15]. As SPE adsorbents, MWCNTs have shown very strong adsorption of phthalate esters [16], chlorophenols [17], 4tert-octylphenol [18], etc. We have used MWCNTs as SPE adsorbents for the successful enrichment of polycyclic aromatic hydrocarbons [19], pyrazole and pyrrole pesticides [20] in environmental water samples.

Inspired by these studies, we used magnetic MWCNTs (magMWCNTs) as MSPE adsorbents to enrich six SUs in environmental water samples, followed by HPLC-DAD determination. Several methods have previously been developed using mag-MWCNTs as the adsorbent for analysis of estrogens [21], nerve agents [22], aconitines [23] and so on. However, to the best of our knowledge, no methods based on mag-MWCNTs have been established for determination of SUs. In this work, mag-MWCNTs were prepared and characterized using scanning electron microscope (SEM) and X-ray diffraction (XRD). Several key factors influencing MSPE efficiency were investigated in detail, including the type and volume of desorption solvent, sample solution $\mathrm{pH}$, salt concentration, amount of mag-MWCNTs, and extraction and desorption time. Response surface methodology was employed for multi-variable optimization.
The MSPE-HPLC method was validated and applied to the simultaneous separation and determination of six SUs in reservoir and tap water samples.

\section{Experimental}

\subsection{Chemical reagents and materials}

Carboxylic MWCNTs ( $>50 \mathrm{~nm}$ I.D., 10-20 $\mu \mathrm{m}$ length) were obtained from Chengdu Organic Chemistry Co., Ltd, Chinese Academy of Sciences (Chengdu, China). Ferric chloride hexahydrate $\left(\mathrm{FeCl}_{3} \cdot 6 \mathrm{H}_{2} \mathrm{O}\right)$ was purchased from Sinopharm Chemical Reagent Co. Ltd. (China). Ethylene glycol was supplied by Fuyu Fine Chemical Co., Ltd. (Tianjin, China). Sodium acetate, sodium hydroxide and absolute ethyl alcohol were purchased from Aibi Chemical Reagent Limited Company (Shanghai, China). Anhydrous sodium chloride was purchased from Jiangsu Powerful Function Chemical Co., Ltd. Phosphoric acid was purchased from Kaixin Chemical Industry co., Ltd (Tianjin, China). Chemicals were of at least analytical grade. Solvents including methanol, acetonitrile and acetone were of HPLC grade and supplied by TEDIA (USA). Ultrapure water $(18.2 \mathrm{M} \Omega \mathrm{cm}$ ) was obtained from a model Synergy 185 ultra-pure water system (Millipore, USA).

Analytical standards of the six SUs (>99\% purity), namely, nicosulfuron, thifensulfuron methyl, metsulfuron methyl, chlorsulfuron, pyrazosulfuron-ethyl, and chlorimuron-ethyl (Fig. 1), were purchased from the Testing Center of the Shanghai Pesticide Research Institute (China). A stock solution of each analyte was prepared at $1000 \mathrm{mg} / \mathrm{L}$ in acetonitrile, and stored at $-18^{\circ} \mathrm{C}$ in the dark. Working standard solutions were prepared by appropriate dilution of stock solutions into an acetonitrile-water solution (20:80, v:v).

Surface water samples were collected from the Qingdao Jihongtan Reservoir, and tap water samples were collected from our laboratory. All water samples were filtered through $0.45-\mu \mathrm{m}$ membranes (Tianjin Jinteng Experiment Equipment Ltd, Co., Tianjin, China) and stored in brown glass bottles at $4{ }^{\circ} \mathrm{C}$ prior to analysis. 


\subsection{Apparatus and software}

Experiments were performed on an Agilent 1100 liquid chromatographic system consisting of a quaternary delivery pump, an auto-sampler, a thermostatic column compartment and a DAD detector. A personal computer equipped with Agilent ChemStation for HPLC was used to process the chromatographic data. An analytical Agela Venusil ASB $\mathrm{C}_{18}(250 \times 4.6 \mathrm{~mm}, 5 \mu \mathrm{m})$ was used to analyze the SUs at $30^{\circ} \mathrm{C}$. The sample injection volume was $20 \mu \mathrm{L}$. Absorbance was monitored at $230 \mathrm{~nm}$. The mobile phase was a gradient prepared from acetonitrile (solvent A) and water (solvent B), the $\mathrm{pH}$ of which was adjusted to 3.0 with phosphoric acid. Gradient elution conditions were as follows: $20 \% \mathrm{~A}(0 \mathrm{~min}), 40 \% \mathrm{~A}$ ( $8 \mathrm{~min}$, hold $9 \mathrm{~min}$ ), 45\% A (18 min, hold $12 \mathrm{~min}$ ). The flow rate was $1 \mathrm{~mL} / \mathrm{min}$. Under these optimum conditions, all studied SUs were well resolved from each other.

Characterization of mag-MWCNTs were conducted on a Tescan XM 5136 scanning electron microscope (SEM, Tescan, Czech Republic) and an X-ray diffractometer (XRD) (Bruker D8 Advance). Matlab 7.5.0.342 (Mathworks Corporation, USA) was employed for study of the response surface.

\subsection{Preparation of mag-MWCNTs}

Mag-MWCNTs were synthesized using a published solvothermal method [24] with slight modification, as schematically shown in Fig. S1. Briefly, $0.5 \mathrm{~g}$ of carboxylic MWCNTs was suspended in $50 \mathrm{~mL}$ of ethylene glycol containing $3 \mathrm{~g}$ of $\mathrm{FeCl}_{3} \cdot 6 \mathrm{H}_{2} \mathrm{O}$ in a $100-$ $\mathrm{mL}$ beaker. After $3.5 \mathrm{~g}$ of sodium acetate was added, the mixture was stirred for $30 \mathrm{~min}$. The resulting solution was allowed to stand at room temperature for $30 \mathrm{~min}$ and the obtained mixture was transferred to a Teflon-lined stainless steel autoclave $(100 \mathrm{~mL})$ and heated to $200^{\circ} \mathrm{C}$ for $16 \mathrm{~h}$. After cooling to room temperature, the synthetic product was sequentially washed with $50 \mathrm{~mL}$ of absolute ethyl alcohol and then three times with $50 \mathrm{~mL}$ of ultra-pure water. The purified mag-MWCNTs were dried under vacuum.

\subsection{MSPE procedure}

Before extraction, $40 \mathrm{mg}$ of mag-MWCNTs were added to a 250$\mathrm{mL}$ beaker and conditioned with $5.0 \mathrm{~mL}$ of methanol and $10.0 \mathrm{~mL}$ of ultra-pure water by stirring for $1 \mathrm{~min}$. The mag-MWCNTs were forced to settle by placing a strong magnet near the bottle, and the water was decanted. Then, $100 \mathrm{~mL}$ of a spiked water sample $(\mathrm{pH}$ adjusted to 3.0 with phosphoric acid) was added and dispersed with stirring for $8 \mathrm{~min}$. Mag-MWCNTs were again forced to settle to the bottom and the supernatant water was decanted and discarded. Wet mag-MWCNTs were then washed twice with $5 \mathrm{~mL}$ of acetone. All acetone extracts were combined and transferred into an autosampler vial. The collected eluate was concentrated with a gentle stream of nitrogen at room temperature, diluted to $0.4 \mathrm{~mL}$ with an acetonitrile-water solution (20:80, v:v), and filtered through a $0.45-\mu \mathrm{m}$ nylon membrane for HPLC analysis. The MSPE procedure is shown schematically in Fig. S1.

\section{Results and discussion}

\subsection{Characterization of the mag-MWCNTs}

The micro-morphologies of the mag-MWCNTs were observed by SEM. As shown in Fig. 2, the spherical $\mathrm{Fe}_{3} \mathrm{O}_{4}$ nanoparticles were well wrapped by the MWCNT bundles to give magnetic-responsive MWCNTs, which could be separated from the matrix solution using an external magnet. Accordingly, Fig. S2 shows observations before and after the MSPE procedure. As shown, the SU solution became black and turbid when mag-MWCNTs were dispersed (Fig. S2A),

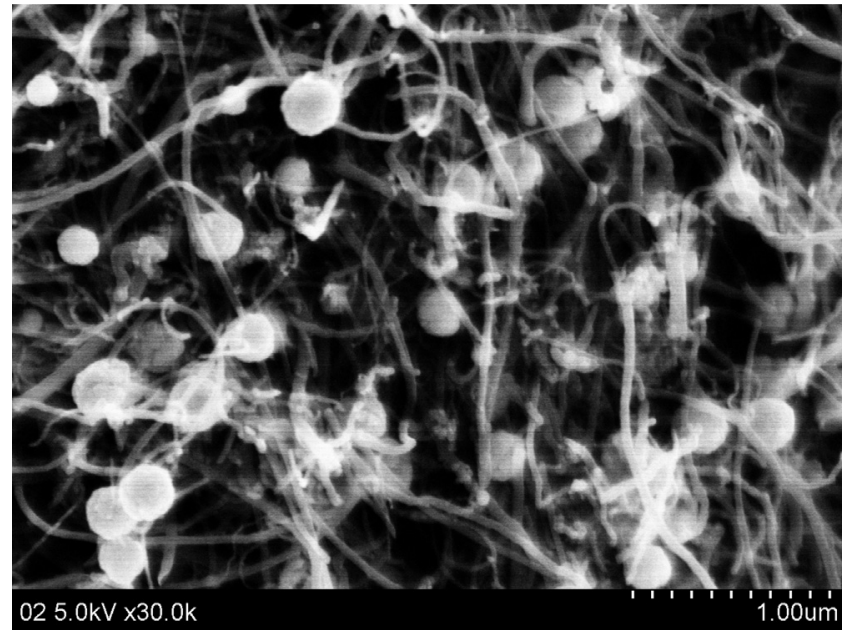

Fig. 2. SEM image of mag-MWCNTs.

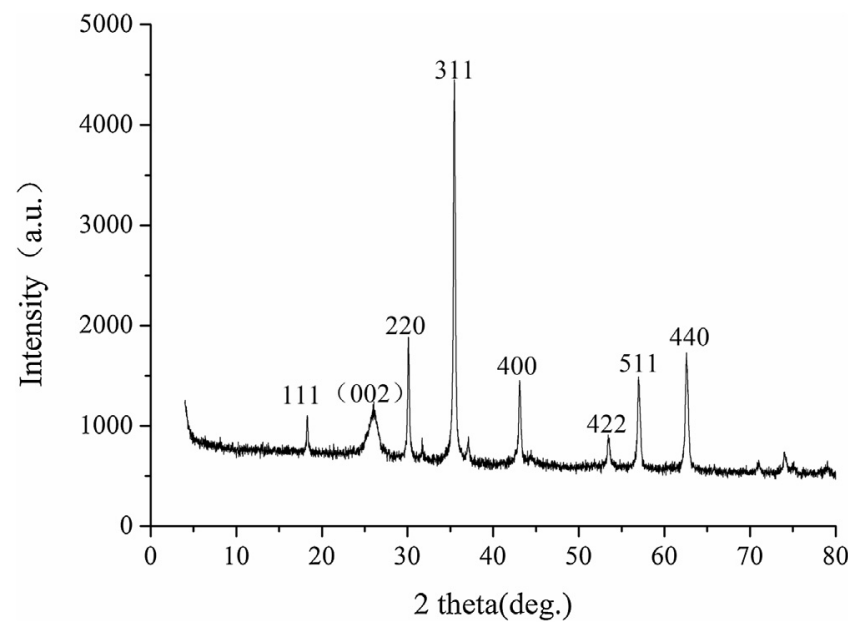

Fig. 3. XRD pattern of mag-MWCNTs.

but the mag-MWCNTs with adsorbed SUs adhered to the inner side wall of the vial when the external magnetic field was applied. As a result, the turbid solution again became clear and transparent, as shown in Fig. S2B. Thus a fast simple magnetic separation was attained.

The mag-MWCNTs were also characterized by XRD. As shown in Fig. 3, peaks at $2 \theta$ values of $30.02^{\circ}(220), 35.06^{\circ}$ (311), $43.32^{\circ}$ $(400), 53.05^{\circ}(422), 57.08^{\circ}(511)$, and $62.92^{\circ}$ (440) can be attributed to the inverse spine crystalline structure of $\mathrm{Fe}_{3} \mathrm{O}_{4}$, consistent with previous reports [25]. The diffraction peak at $2 \theta$ of $26.04^{\circ}$ is the typical Bragg peak of pristine MWCNTs and can be indexed to the (002) reflection of graphite [26]. Therefore, the mag-MWCNTs were successfully prepared.

\subsection{Optimization of MSPE procedure}

MSPE efficiency is mainly subject to the following major factors: amount of mag-MWCNTs, sample solution $\mathrm{pH}$, extraction and desorption time, amount of salt added, and type and volume of desorption solvent. In this study, these were investigated using a spiked ultrapure water sample $(0.5 \mu \mathrm{g} / \mathrm{L})$. First, the type and volume of desorption solvent, sample solution $\mathrm{pH}$, and the amount of salt added were investigated individually. The other three factors 
(amount of mag-MWCNTs, extraction time and desorption time) were evaluated using response surface experiments.

\subsubsection{Effect of type of desorption solvent}

Desorption solvent is known to be an important factor that can significantly affect MSPE efficiency. Three solvents-methanol, acetonitrile and acetone-were studied as desorption solvents to examine their effect on extraction efficiency. Fig. 4A shows that acetonitrile and acetone provided better results than methanol. The best extraction efficiency was obtained by using acetone, which can disrupt interactions between mag-MWCNTs and SUs, and elute SUs effectively. Therefore, acetone was adopted as the desorption solvent for the remainder of this study.

\subsubsection{Effect of volume of desorption solvent}

The volume of desorption solvent is thought to have a marked effect on the desorption efficiency of MSPE and thereby the analytical sensitivity of the proposed method. To investigate the effect of volume of desorption solvent, 5, 10 and $15 \mathrm{~mL}$ of acetone were used. The results shown in Fig. 4B reveal that $10 \mathrm{~mL}$ of acetone is sufficient for quantitative desorption. This volume is low while still offering quantitative and reproducible elution. In further experiments, $10 \mathrm{~mL}$ of acetone was selected for desorption.

\subsubsection{Effect of sample $p H$}

It is well known that the analyte species in solution usually depends on solution $\mathrm{pH}$, as does analyte stability. The $\mathrm{pH}$ of the sample solution plays an important role in the adsorption of SUs by affecting both the form of the SUs and the surface binding sites of the mag-MWCNTs. The effect of solution $\mathrm{pH}$ (ranging from 2 to 7) on SU extraction was investigated. As shown in Fig. 4C, at low pH $(\mathrm{pH}=2.0)$, the recoveries of all SUs were low. This was probably due to partial decomposition of the SUs in acidic condition. The extraction efficiencies for the six SUs increased at $\mathrm{pH} 2-3$. The highest signals were obtained when the samples were prepared at $\mathrm{pH} 3$; signals again decreased when $\mathrm{pH}>3$. There was no marked difference between $\mathrm{pH} 4.0$ and 7.0. It is very likely that the six SUs are weakly acidic herbicides whose pKa values lie between 3.3 and 4.6, and they are extracted through both electrostatic interaction and $\pi-\pi$ stacking. The carboxyl groups on carboxylic MWCNTs surfaces enhance electrostatic interactions and may serve as chelation sites for the formation of hydrogen bonds that increase extraction efficiency. At pH 5-7, most SUs are negatively charged, the carboxylic MWCNTs are ionized and negative, and SUs can no longer interact with MWCNTs through electrostatic interactions. At pH 3.0, SUs are neutral and have high affinity for the adsorbent through hydrogen bonds and $\pi-\pi$ interactions. Therefore, sample solutions at $\mathrm{pH} 3$ were used in further experiments.

\subsubsection{Effect of salt}

Salt content in water samples can disrupt the solvation cage of water-soluble analytes or alter the diffusion rate of analytes from aqueous to solid phases. To investigate the effect of salt on the extraction of SUs, various amounts of $\mathrm{NaCl}(0,0.5,1,5$ and $10 \%$, $\mathrm{w} / \mathrm{v}$ ) were added into solution to adjust salinity. As shown in Fig. 4D, recovery of SUs decreased when the concentration of $\mathrm{NaCl}$ varied from 0 to $0.5 \%$, but remained nearly constant for pyrazosulfuronethyl and chlorimuron-ethyl, while increasing for other SUs as the $\mathrm{NaCl}$ concentration increased from 0.5 to $10 \%$. Notably, the highest recoveries were obtained when no $\mathrm{NaCl}$ was added. Possible explanations are as follows. $\mathrm{NaCl}$ may reduce mass transfer by increasing the thickness of the Nernst diffusion layer [27], since in sample solutions at $\mathrm{pH} 3$, the carboxyl groups on mag-MWCNTs surfaces were charged and showed partial electrostatic interactions with $\mathrm{NaCl}$. Accordingly, the diffusion rate of SUs to the surface of the MWCNTs decreased, resulting in longer adsorption times to reach equilibrium and decreased extraction efficiency when $\mathrm{NaCl}$ increased from 0 to $0.5 \%$. Alternatively, the addition of salt could decrease SU solubility in aqueous samples and thus benefit the extraction [27], leading to increased efficiency as the $\mathrm{NaCl}$ content increased from 0.5 to $10 \%$. On the basis of these results, considering the slight difference in extraction efficiency between 0 and $10 \% \mathrm{NaCl}$ (Fig. 4D), and for the sake for simplicity and economy, $\mathrm{NaCl}$ was not added in subsequent experiments.

\subsubsection{Response surface for optimization of other conditions of MSPE}

The remaining three parameters (amount of mag-MWCNTs, extraction time and desorption time) were optimized by response surface experimental design. These response surfaces were obtained for two experimental factors while the third was held constant at its optimum level. The amount of mag-MWCNTs can directly affect extraction efficiency for SUs. Insufficient magMWCNTs might cause breakthrough of SUs, whereas excessive mag-MWCNTs will increase the cost and time of analysis. Fig. 5 shows a three-dimensional representation of the response surfaces (in recovery) for metsulfuron methyl, as an example. As shown in the figure, high extraction recovery was achieved when $40 \mathrm{mg}$ of mag-MWCNTs were added with an extraction time of $8 \mathrm{~min}$ and desorption time of $2 \mathrm{~min}$. The highest extraction recoveries were not achieved for nicosulfuron and chlorimuron-ethyl (data not shown) when $40 \mathrm{mg}$ mag-MWCNTs were added. Nevertheless, when considering the overall high extraction recoveries for all six SUs, the three optimal parameters were established: magMWCNTs, $40 \mathrm{mg}$; extraction time, $8 \mathrm{~min}$; desorption time, $2 \mathrm{~min}$.

\subsection{Analytical performance of the mag-MWCNTS-MSPE-HPLC method}

Under the above-optimized MSPE conditions, the six SUs were separated well by HPLC and the analytical performance of the mag-MWCNTs-based MSPE method was assessed. Six SU standard solutions with different concentrations $(0.05,0.1,0.4,1.0,2.0$, and $5.0 \mu \mathrm{g} / \mathrm{L}$ for individual SU) were obtained by serial dilution with pure water from a stock solution. Calibration curves were obtained using a least-squares linear regression analysis of peak area versus SU concentration. The method gives excellent linearity in the range of $0.05-5.0 \mu \mathrm{g} / \mathrm{L}$ for six SUs, with coefficients of correlation $(r)$ ranging from 0.9994 to 0.9998 , as listed in Table 1.

The preconcentration factors for all six SUs, which were obtained by comparing the slopes of the calibration curves before and after the MSPE procedure, ranged from 178 to 210, as shown in Table S1. This suggested that MSPE has high enrichment ability. The limits of detection (LODs) for the method, calculated according to peak height by analyzing the spiked water sample after pretreatment using a signal-to-noise ratio of 3, ranged from 0.01 to $0.04 \mu \mathrm{g} / \mathrm{L}$ (Table 1 ). With a target of peak height that is $10-$ fold higher background noise $(\mathrm{S} / \mathrm{N}=10)$, the limits of quantification (LOQs) were obtained from 0.03 to $0.13 \mu \mathrm{g} / \mathrm{L}$ (Table 1 ). The LODs for all six SUs are much lower than both the maximum residue level (MRL) of $0.1 \mu \mathrm{g} / \mathrm{L}$ for a single pesticide in drinking water (98/83/EC by the European legislation) [28] and the MRL of $1 \mu \mathrm{g} / \mathrm{L}$ in European Union surface water intended for use in drinking water regulations (75/440/EEC) [29]. Thus, this method meets the requirements of MRL detection for these six SUs in drinking water and surface water samples. The intra-day and inter-day precision in terms of peak area, based on six consecutive injections, are shown in Table 2. As shown, the relative standard deviations (RSDs) of peak area, obtained from a working solution containing each of six herbicides at three spiked concentrations $(0.1,2$ and $4 \mu \mathrm{g} / \mathrm{L})$ based on intraday precisions, were $2.0-11.0 \%$, while the RSDs based on inter-day 

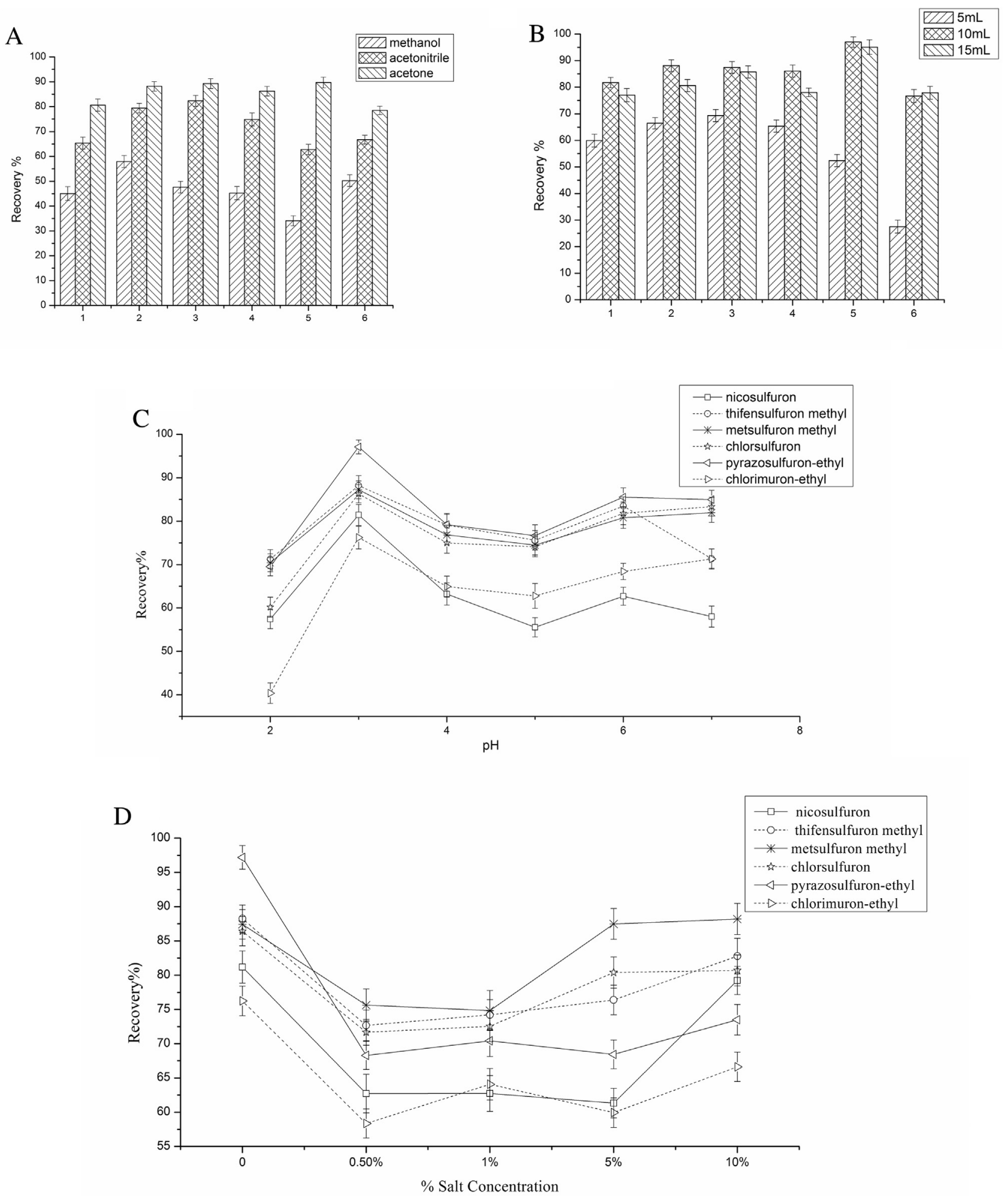

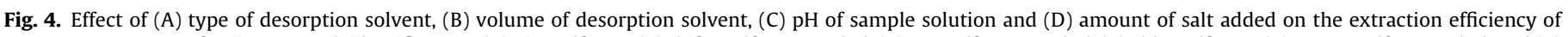

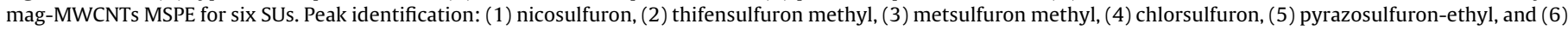

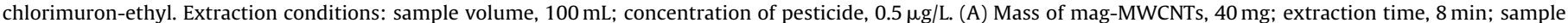

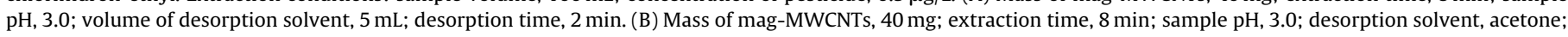

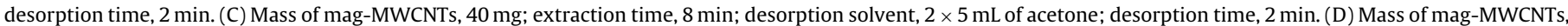
$40 \mathrm{mg}$; extraction time, $8 \mathrm{~min}$; sample $\mathrm{pH}$, 3.0; desorption solvent, $2 \times 5 \mathrm{~mL}$ acetone; desorption time, $2 \mathrm{~min}$.

precision ranged from $2.1-12.9 \%$. Thus, mag-MWCNTs are ideal candidate adsorbents for MSPE, and the MSPE-HPLC method is proven highly sensitive and accurate for simultaneous enrichment and determination of six SUs at trace levels.

\subsection{Method performance comparison}

Analytical performance of the developed MSPE-HPLC-DAD method for the detection of SUs was compared with reported 


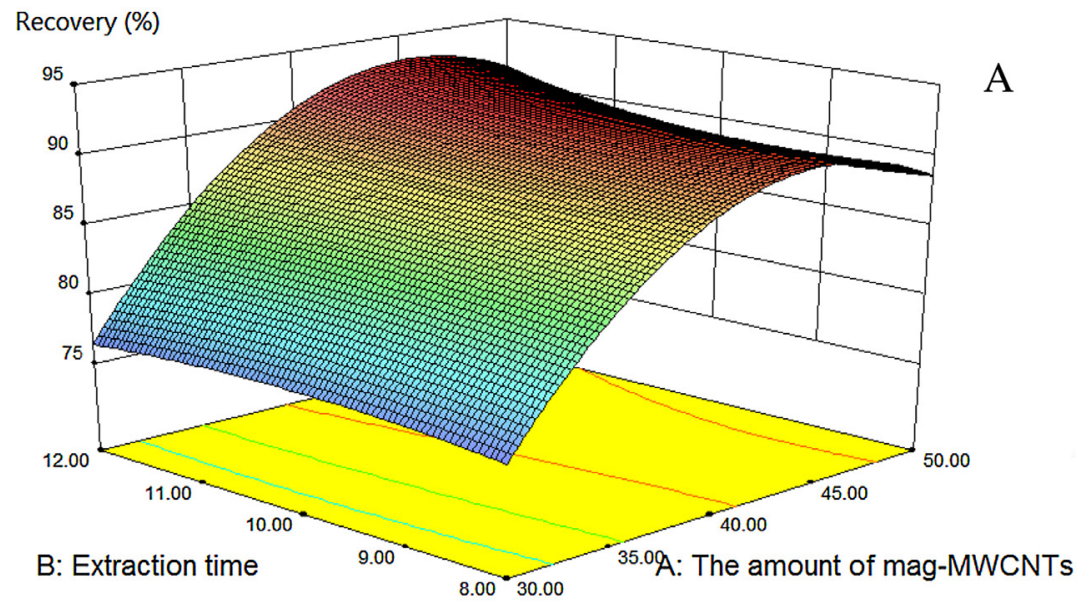

B

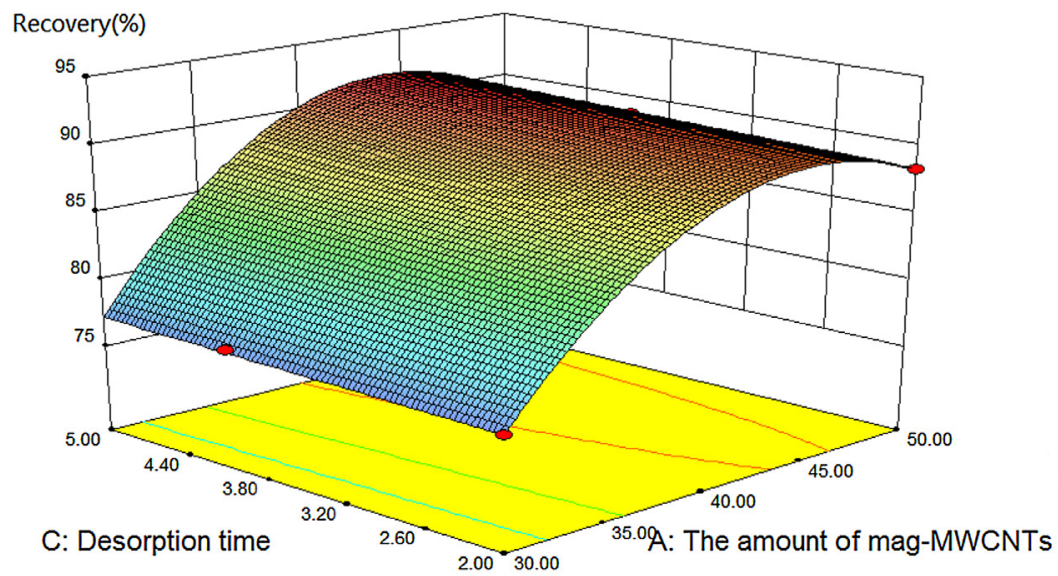

$\mathrm{C}$

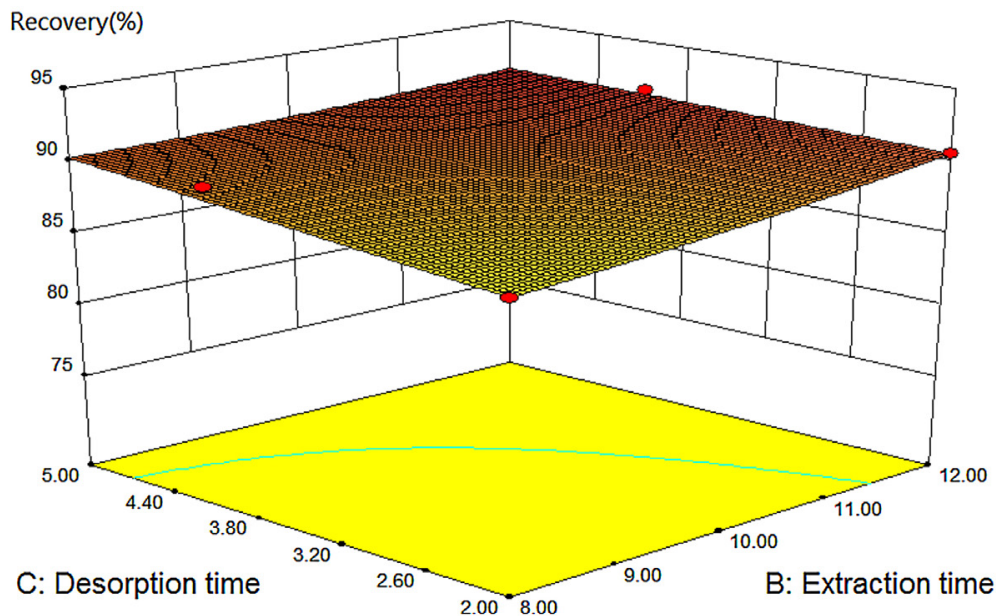

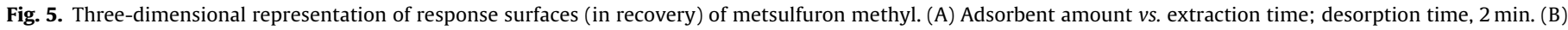
Adsorbent amount $v s$. desorption time; extraction time, $8 \mathrm{~min}$. (C) Desorption time vs. extraction time; adsorbent mass, $40 \mathrm{mg}$.

HPLC methods. As shown in Table S2, a pretreatment time of less than $15 \mathrm{~min}$ is significantly shorter than conventional SPE (2-7 h) $[2,5,8]$. In comparison with reported MSPE-based methods $[13,30]$, our method presents lower LODs for more SUs. Furthermore, considering economic costs, MWCNTs and iron salt precursors are commercially available and relatively inexpensive. Mag-MWCNTs can be reused for at least six adsorption-desorption cycles, as nearly constant recovery values are obtained with relative error less than $3 \%$. Thus, the method presented here has advantages of high sen- 
Table 1

Related analytical parameters of the mag-MWCNT-MSPE-HPLC method for determination of six SUs.

\begin{tabular}{|c|c|c|c|c|c|}
\hline SUs & Regression equation $^{\mathrm{a}}$ & Coefficient of correlation (r) & Linear range $(\mu \mathrm{g} / \mathrm{L})$ & $\operatorname{LOD}(\mu \mathrm{g} / \mathrm{L})$ & $\mathrm{LOQ}(\mu \mathrm{g} / \mathrm{L})$ \\
\hline Nicosulfuron & $y=9.473 x+0.258$ & 0.9997 & $0.05-5.0$ & 0.04 & 0.13 \\
\hline Thifensulfuron methyl & $y=15.70 x+0.467$ & 0.9997 & $0.05-5.0$ & 0.03 & 0.10 \\
\hline Metsulfuron methyl & $y=17.39 x+0.432$ & 0.9997 & $0.05-5.0$ & 0.01 & 0.03 \\
\hline Chlorsulfuron & $y=17.89 x+0.328$ & 0.9998 & $0.05-5.0$ & 0.01 & 0.03 \\
\hline Pyrazosulfuron-ethyl & $y=11.94 x+0.457$ & 0.9994 & $0.05-5.0$ & 0.02 & 0.07 \\
\hline Chlorimuron-ethyl & $y=11.88 x+0.444$ & 0.9996 & $0.05-5.0$ & 0.02 & 0.07 \\
\hline
\end{tabular}

a $x$ means concentration of SUs $(\mu \mathrm{g} / \mathrm{L}), y$ means peak area.

Table 2

Intra-day and inter-day precisions (RSD, \%) for MSPE-HPLC determination of the six SUs.

\begin{tabular}{|c|c|c|c|}
\hline SUs & Spiked $(\mu \mathrm{g} / \mathrm{L})$ & Intra-day $(n=6)$ & Inter-day $(n=6)$ \\
\hline \multirow[t]{3}{*}{ Nicosulfuron } & 0.1 & 8.1 & 12.9 \\
\hline & 2 & 6.0 & 5.9 \\
\hline & 4 & 3.9 & 7.3 \\
\hline \multirow[t]{3}{*}{ Thifensulfuron methyl } & 0.1 & 9.3 & 11.0 \\
\hline & 2 & 5.6 & 5.7 \\
\hline & 4 & 2.0 & 4.1 \\
\hline \multirow[t]{3}{*}{ Metsulfuron methyl } & 0.1 & 8.0 & 8.2 \\
\hline & 2 & 4.4 & 2.2 \\
\hline & 4 & 5.1 & 4.4 \\
\hline \multirow[t]{3}{*}{ Chlorsulfuron } & 0.1 & 7.6 & 8.8 \\
\hline & 2 & 4.7 & 3.4 \\
\hline & 4 & 2.4 & 4.5 \\
\hline \multirow[t]{3}{*}{ Pyrazosulfuron-ethyl } & 0.1 & 11.0 & 10.5 \\
\hline & 2 & 3.3 & 5.6 \\
\hline & 4 & 4.4 & 7.8 \\
\hline \multirow[t]{3}{*}{ Chlorimuron-ethyl } & 0.1 & 8.6 & 11.1 \\
\hline & 2 & 3.7 & 2.1 \\
\hline & 4 & 6.7 & 8.2 \\
\hline
\end{tabular}

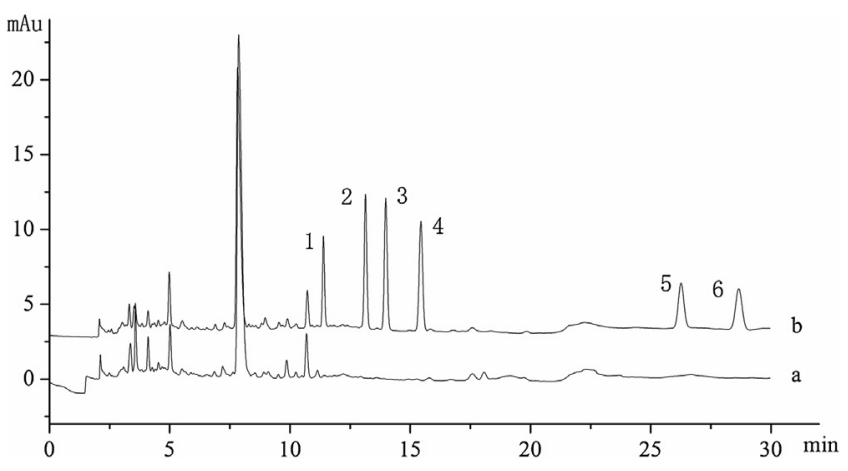

Fig. 6. HPLC chromatograms of six SUs in real-life water samples after MSPE without spiking (a) and with spiking (b). Spiked concentration of SU standard was $4.0 \mu \mathrm{g} / \mathrm{L}$. MSPE conditions: sample volume, $100 \mathrm{~mL}$; amount of mag-MWCNTs, $40 \mathrm{mg}$; extraction time, $8 \mathrm{~min}$; desorption solvent, $10 \mathrm{~mL}$ acetone; desorption time, $2 \mathrm{~min}$; sample pH, 3. Peak identification as described in Fig. 4.

sitivity, cost-effectiveness, excellent reusability and rapid, simple magnetic separation.

\subsection{Application of the MSPE-HPLC to real environmental water samples}

To further evaluate the practical applicability of the MSPE-HPLC method, two water samples from reservoir water and tap water were analyzed. The MSPE elution solutions were analyzed by HPLC and the results are shown in Fig. 6. No endogenous SUs were detected in the real water samples (Fig. 6a), and significant peaks appeared after spiking (Fig. 6b). The recoveries were obtained with spiked real water samples with $0.1,2.0$ and $4.0 \mu \mathrm{g} / \mathrm{L}$ individual herbicides, which were averaged from three replicates. As listed in Table 3, the recovery of six SUs ranged from 76.7-106.9\% with RSDs of $0.7-9.8 \%$ for reservoir water samples, and ranged from $78.2-105.4 \%$ with RSDs of $1.6-11.3 \%$ for tap water samples. The results indicate that the MSPE-HPLC method is practically feasible for highly efficient separation, extraction and determination of trace SUs in complex water samples.

\section{Conclusions}

In conclusion, a simple, sensitive, and robust mag-MWCNTsbased MSPE method was successfully developed for the simultaneous determination of six SUs in environmental water samples followed by HPLC-DAD. High extraction efficiency and low LODs/LOQs were obtained. The assay requires no complex devices, as the mag-MWCNTs are separated quickly from solutions by an external magnet. The processes of enrichment, separation, and desorption for six SUs are convenient, rapid, cost/labor-effective and eco-friendly. The developed MSPE-HPLC-DAD method provides great potential for analyzing SUs in real water samples.

\section{Conflict of interest}

The authors declare no conflict of interest.

\section{Acknowledgments}

The authors acknowledge support from the National Natural Science Foundation of China (21547002, 51478230, 21477160), the Taishan Scholar Construction Project Special Foundation (2010016010) and the Special Foundation of Central Financial Support to Local Colleges and Universities (201020029). The authors acknowledge Prof. Xingliang Song for his assistance in response surface experimental design. 
Table 3

Determination of six SUs and method recoveries in real water samples.

\begin{tabular}{|c|c|c|c|c|c|}
\hline \multirow[t]{2}{*}{ SUs } & \multirow{2}{*}{$\begin{array}{l}\text { Spiked } \\
(\mu \mathrm{g} / \mathrm{L})\end{array}$} & \multicolumn{2}{|c|}{ Reservoir water } & \multicolumn{2}{|l|}{ Tap water } \\
\hline & & Found $(\mu \mathrm{g} / \mathrm{L})$ & Recovery $(\%, n=3)$ & Found $(\mu \mathrm{g} / \mathrm{L})$ & Recovery $(\%, n=3)$ \\
\hline \multirow[t]{4}{*}{ Nicosulfuron } & 0 & $\mathrm{ND}^{\mathrm{a}}$ & & ND & \\
\hline & 0.10 & 0.107 & $106.9 \pm 9.8^{\mathrm{b}}$ & 0.097 & $96.8 \pm 8.0$ \\
\hline & 2.00 & 1.75 & $87.3 \pm 8.0$ & 1.67 & $83.3 \pm 8.0$ \\
\hline & 4.00 & 3.67 & $91.8 \pm 3.7$ & 3.98 & $99.5 \pm 6.7$ \\
\hline \multirow[t]{4}{*}{ Thifensulfuron methyl } & 0 & ND & & ND & \\
\hline & 0.10 & 0.085 & $84.9 \pm 7.5$ & 0.069 & $99.3 \pm 2.0$ \\
\hline & 2.00 & 1.99 & $99.7 \pm 3.4$ & 1.73 & $86.3 \pm 7.9$ \\
\hline & 4.00 & 4.06 & $101.5 \pm 4.9$ & 3.89 & $97.2 \pm 2.7$ \\
\hline \multirow[t]{4}{*}{ Metsulfuron methyl } & 0 & ND & & ND & \\
\hline & 0.10 & 0.090 & $90.2 \pm 6.3$ & 0.090 & $90.0 \pm 5.4$ \\
\hline & 2.00 & 1.95 & $97.7 \pm 4.8$ & 1.66 & $83.2 \pm 10.3$ \\
\hline & 4.00 & 3.95 & $98.7 \pm 8.2$ & 3.71 & $92.8 \pm 3.7$ \\
\hline \multirow[t]{4}{*}{ Chlorsulfuron } & 0 & ND & & ND & \\
\hline & 0.10 & 0.077 & $76.7 \pm 7.2$ & 0.105 & $105.4 \pm 9.3$ \\
\hline & 2.00 & 1.95 & $97.4 \pm 4.9$ & 1.75 & $87.3 \pm 11.3$ \\
\hline & 4.00 & 4.06 & $101.4 \pm 2.7$ & 4.04 & $101.1 \pm 3.3$ \\
\hline \multirow[t]{4}{*}{ Pyrazosulfuron-ethyl } & 0 & ND & & ND & \\
\hline & 0.10 & 0.087 & $87.3 \pm 9.5$ & 0.081 & $81.5 \pm 4.2$ \\
\hline & 2.00 & 1.85 & $92.6 \pm 0.7$ & 1.74 & $86.8 \pm 5.0$ \\
\hline & 4.00 & 4.01 & $100.4 \pm 3.0$ & 3.97 & $99.3 \pm 7.5$ \\
\hline \multirow[t]{4}{*}{ Chlorimuron-ethyl } & 0 & ND & & ND & \\
\hline & 0.10 & 0.106 & $105.7 \pm 7.9$ & 0.078 & $78.2 \pm 1.6$ \\
\hline & 2.00 & 1.92 & $96.0 \pm 5.5$ & 1.86 & $93.0 \pm 4.3$ \\
\hline & 4.00 & 4.07 & $101.7 \pm 7.9$ & 4.12 & $103.1 \pm 3.2$ \\
\hline
\end{tabular}

a Not detected.

b RSD.

\section{Appendix A. Supplementary data}

Supplementary data associated with this article can be found, in the online version, at http://dx.doi.org/10.1016/j.chroma.2016.08. 065.

\section{References}

[1] R.L. Anderson, N.E. Humburg, Field duration of chlorsulfuron bioactivity in the central great plains, J. Environ. Qual. 16 (1987) 263-266.

[2] R. Gallitzendörfer, T. Timm, D. Koch, M. Kuüsters, M. Gerhartz, Simultaneous determination of 12 sulfonylurea herbicides in drinking water after SPE by LC-DAD, Chromatographia 73 (2011) 813-816.

[3] J.B. Chao, J.F. Liu, M.J. Wen, J.M. Liu, Y.Q. Cai, G.B. Jiang, Determination of sulfonylurea herbicides by continuous-flow liquid membrane extraction on-line coupled with high-performance liquid chromatography, J. Chromatogr. A 955 (2002) 183-189.

[4] Q.H. Wu, C. Wang, Z.M. Liu, C.X. Wu, X. Zeng, J.L. Wen, Z. Wang, Dispersive solid-phase extraction followed by dispersive liquid-liquid microextraction for the determination of some sulfonylurea herbicides in soil by high-performance liquid chromatography, J. Chromatogr. A 1216 (2009) 5504-5510.

[5] G.Z. Fang, J. Chen, J.P. Wang, J.X. He, S. Wang, N-Methylimidazolium ionic liquid-functionalized silica as a sorbent for selective solid-phase extraction of 12 sulfonylurea herbicides in environmental water and soil samples, J. Chromatogr. A 1217 (2010) 1567-1574.

[6] Q.Z. Zhu, P. Degelmann, R. Niessner, D. Knopp, Selective trace analysis of sulfonylurea herbicides in water and soil samples based on solid-phase extraction using a molecularly imprinted polymer, Environ. Sci. Technol. 36 (2002) 5411-5420.

[7] E. Ayano, H. Kanazawa, M. Ando, T. Nishimura, Determination and quantitation of sulfonylurea and urea herbicides in water samples using liquid chromatography with electrospray ionization mass spectrometric detection, Anal. Chim. Acta 507 (2004) 211-218.

[8] C.M. Yan, B.B. Zhang, W.Y. Liu, F. Feng, Y.G. Zhao, H. Du, Rapid determination of sixteen sulfonylurea herbicides in surface water by solid phase extraction cleanup and ultra-high-pressure liquid chromatography coupled with tandem mass spectrometry, J. Chromatogr. B 879 (2011) 3484-3489.

[9] L.Q. Yang, X.M. Zhao, J. Zhou, Selective enrichment and determination of nicosulfuron in water and soil by a stir bar based on molecularly imprinted polymer coatings, Anal. Chim. Acta 670 (2010) 72-77.

[10] A. Gure, F.J. Lara, D. Moreno-González, N. Megersa, M.D. Olmo-Iruela, A.M. García-Campaña, Salting-out assisted liquid-liquid extraction combined with capillary HPLC for the determination of sulfonylurea herbicides in environmental water and banana juice samples, Talanta 127 (2014) 51-58.

[11] X.M. Liu, Z.W. Sun, G. Chen, W.W. Zhang, Y.P. Cai, R.M. Kong, X.Y. Wang, Y.R. Suo, J.M. You, Determination of phthalate esters in environmental water by magnetic zeolitic imidazolate framework-8 solid-phase extraction coupled with high-performance liquid chromatography, J. Chromatogr. A 1409 (2015) 46-52.

[12] J. Yang, J.Y. Li, J.Q. Qiao, H.Z. Lian, H.Y. Chen, Solid phase extraction of magnetic carbon doped $\mathrm{Fe}_{3} \mathrm{O}_{4}$ nanoparticles, J. Chromatogr. A 1325 (2014) 8-15.

[13] Z.Y. He, D.H. Liu, R.H. Li, Z.Q. Zhou, P. Wang, Magnetic solid-phase extraction of sulfonylurea herbicides in environmental water samples by $\mathrm{Fe}_{3} \mathrm{O}_{4} @$ dioctadecyl dimethyl ammonium chloride@silica magnetic particles, Anal. Chim. Acta 747 (2012) 29-35.

[14] H.Y. Niu, Y.Q. Cai, Y.L. Shi, F.S. Wei, J.M. Liu, S.F. Mou, G.B. Jiang, Evaluation of carbon nanotubes as a solid-phase extraction adsorbent for the extraction of cephalosporins antibiotics, sulfonamides and phenolic compounds from aqueous solution, Anal. Chim. Acta 594 (2007) 81-92.

[15] S. Wang, P. Zhao, G. Min, G.Z. Fang, Multi-residue determination of pesticides in water using multi-walled carbon nanotubes solid-phase extraction and gas chromatography-mass spectrometry, J. Chromatogr. A 1165 (2007) 166-171.

[16] Y.Q. Cai, G.B. Jiang, J.F. Liu, Q.X. Zhou, Multi-walled carbon nanotubes packed cartridge for the solid-phase extraction of several phthalate esters from water samples and their determination by high performance liquid chromatography, Anal. Chim. Acta 494 (2003) 149-156.

[17] Y.Q. Cai, Y.E. Cai, S.F. Mou, Y.Q. Lu, Multi-walled carbon nanotubes as a solid-phase extraction adsorbent for the determination of chlorophenols in environmental water samples, J. Chromatogr. A 1081 (2005) 245-247.

[18] Y.Q. Cai, G.B. Jiang, J.F. Liu, Q.X. Zhou, Multiwalled carbon nanotubes as a solid-phase extraction adsorbent for the determination of bisphenol A 4-n-nonylphenol, and 4-tert-octylphenol, Anal. Chem. 75 (2003) 2517-2521.

[19] J.P. Ma, R.H. Xiao, J.H. Li, J.B. Yu, Y.Q. Zhang, L.X. Chen, Determination of 16 polycyclic aromatic hydrocarbons in environmental water samples by solid-phase extraction using multi-walled carbon nanotubes as adsorbent coupled with gas chromatography-mass spectrometry, J. Chromatogr. A 1217 (2010) 5462-5469.

[20] J.P. Ma, X. Lu, Y. Xia, F.L. Yan, Determination of pyrazole and pyrrole pesticides in environmental water samples by solid-phase extraction using multi-walled carbon nanotubes as adsorbent coupled with high-performance liquid chromatography, J. Chromatogr. Sci. 53 (2015) 380-384.

[21] J. Ding, Q. Gao, X.S. Li, W. Huang, Z.G. Shi, Y.Q. Feng, Magnetic solid-phase extraction based on magnetic carbon nanotube for the determination of estrogens in milk, J. Sep. Sci. 34 (2011) 2498-2504.

[22] D. Pardasani, P.K. Kanaujia, A.K. Purohit, A.R. Shrivastava, D.K. Dubey, Magnetic multi-walled carbon nanotubes assisted dispersive solid phase extraction of nerve agents and their markers from muddy water, Talanta 86 (2011) 248-255.

[23] H.F. Zhang Y.P. Shi, Preparation of $\mathrm{Fe}_{3} \mathrm{O}_{4}$ nanoparticle enclosure hydroxylated multi-walled carbon nanotubes for the determination of aconitines in human serum samples, Anal. Chim. Acta 724 (2012) 54-60.

[24] N. Rastkari, R. Ahmadkhaniha, Magnetic solid-phase extraction based on magnetic multi-walled carbon nanotubes for the determination of phthalate monoesters in urine samples, J. Chromatogr. A 1286 (2013) 22-28. 
[25] Y.B. Luo, Q.W. Yu, B.F. Yuan, Y.Q. Feng, Fast microextraction of phthalate acid esters from beverage, environmental water and perfume samples by magnetic multi-walled carbon nanotubes, Talanta 90 (2012) 123-131.

[26] T.T. Baby, S. Ramaprabhu, $\mathrm{SiO}_{2}$ coated $\mathrm{Fe}_{3} \mathrm{O}_{4}$ magnetic nanoparticle dispersed multiwalled carbon nanotubes based amperometric glucose biosensor, Talanta 80 (2010) 2016-2022

[27] B. Chen, S. Wang, O.M. Zhang, Y.M. Huang, Highly stable magnetic multiwalled carbon nanotube composites for solidphase extraction of linear alkylbenzene sulfonates in environmental water samples prior to high-performance liquid chromatography analysis, Analyst 137 (2012) 1232-1240.
[28] European Union Council Directive 98/83/EC on the quality of water intended for human consumption (1998). Off. J. Eur. Commun. (L330): 32.

[29] 75/440/EEC. Concerning the quality required of surface water intended for the abstraction of drinking water in the Member States (EU).

[30] Z.Y. He, D.H. Liu, Z.Q. Zhou, P. Wang, Ionic-liquid-functionalized magnetic particles as an adsorbent for the magnetic SPE of sulfonylurea herbicides in environmental water samples, J. Sep. Sci. 36 (2013) 3226-3233. 